\title{
Science for food
}

\section{Molecular biology contributes to the production and preparation of food}

\author{
Howard Wolinsky ${ }^{1}$ \& Kristofor Husted ${ }^{2}$
}

\begin{abstract}
A lmost 200 years ago, his study of pea plants enabled Gregor Johann Mendel (1822-1884) to discover the laws of inheritance and launch the science of genetics. Now, advances in cellular engineering, synthetic biology, molecular biology, food science, and other technologies are shaping a new world of food preparation, inspiring researchers and renowned chefs to fill the bellies of epicures and the masses. These new technologies not only help to satisfy sophisticated palates but could also address larger problems in food supply that result from increasing population numbers, global climate change, and dwindling natural resources.
\end{abstract}

\section{"Switch on a modern cooking show and you will see chefs using molecular techniques such as freezing in liquid nitrogen or compression cookers"}

Walter White, the high school chemistry teacher turned drug lord in the American TV series Breaking Bad, often said: "Respect the chemistry". Professional chefs at high-end restaurants are respecting not only the chemistry, but also the biology when they add the naturally occurring enzyme transglutaminase - known on the street as "meat glue" - to bond different meats together to create new dishes and dining experiences. Meanwhile, mass-market food chains and providers of food to institutions such as hospitals, universities, schools, or prisons use transglutaminase to stretch their provisions and control costs by bonding together scraps of meat into larger portions.
"The pro is you can have all kinds of interesting restructured meat. You can use bits and pieces and put together a steak or a roast”, said Joe Regenstein, a food scientist in the College of Agriculture and Food Science at Cornell University in Ithaca, NY, USA. "The negative is that because you're putting together pieces of meat, you have to have very high sanitation. If you're undercooking meat, you have the potential for bacteria to get inside the meat. In general, most regular meats are sterile, and most of the bacteria is on the surfaces".

$\mathrm{R}$ egenstein, a fish expert, said transglutaminase works with any meat and fish in any combination: The enzyme just sets off a basic chemical reaction to create bonds between proteins. "You could take three or four pieces of chuck [a cheaper cut of beef] and trim and make it up to look like a sirloin steak. You recreate something much bigger than the pieces you start with", he said. "You can have what looks to be a thicker, more expensive piece of meat for a lower cost”. He said some eateries might not inform consumers that they are being served restructured meat, but retailers are required to disclose this.

High-end restaurants, on the other hand, trumpet their creativity with food combinations made using transglutaminase. David Arnold, Director of Technology at the French Culinary Institute in New York City, USA, said the enzyme helps to get chefs' creative juices flowing. "I can take stacks of chicken skin and glue them together and then cook them almost like sweetbreads and fry them off. I've done layers and different colors of fish and then compressed them to a different shape and then re-sliced them so they looked like a wood grain. You can make very interesting roulades. You can do boneless turduckens [turkey-duck-chicken combinations] that looked like pinwheels on the inside", he said. Transglutaminase could be used to make low-salt sausages that do not require salt for binding. More indulgently, he said, "You can glue fat around pieces of meat that don't otherwise have fat". He added: "I like meat glue because it lets me make things that I couldn't otherwise make and make things that I think are delicious that I couldn't achieve in a different way. There are people who use [transglutaminase] for economy reasons, but I don't”.

... there are even more tools catching on that bring out bold flavors in meals and provide delicious alternatives for diners with special dietary needs"

William Meyers, executive chef at the Stone Harbor Golf Club (Atlantic City, NJ, USA), said he is asked daily whether his dishes are gluten free-something that was not a big concern a decade ago. Today, meat glue can be used in place of flour as a binder for dishes for diners with a gluten allergy. "Scallops are a big dish for us because we're right near the ocean", he said. "I'll glue scallops together in a line and then wrap it with prosciutto. Then I'll wrap it in plastic wrap, vacuum the oxygen out so it stays tight". He then cooks it in a water bath, and when it's finished, the glue sets and he has a log of scallops he can cut up and serve to diners not looking for an upset digestive system. Ultimately, Meyers said, all these techniques not only help the chef prepare food more efficiently and creatively, but also help to bring out flavors and tastes.

\footnotetext{
1 Freelance writer in Chicago, IL, USA. E-mail: wolinsky@ameritech.net

2 Public radio reporter in Columbia, MO, USA. E-mail: kris.husted@gmail.com

DOI 10.15252/embr.201540128 | Published online 17 February 2015
} 


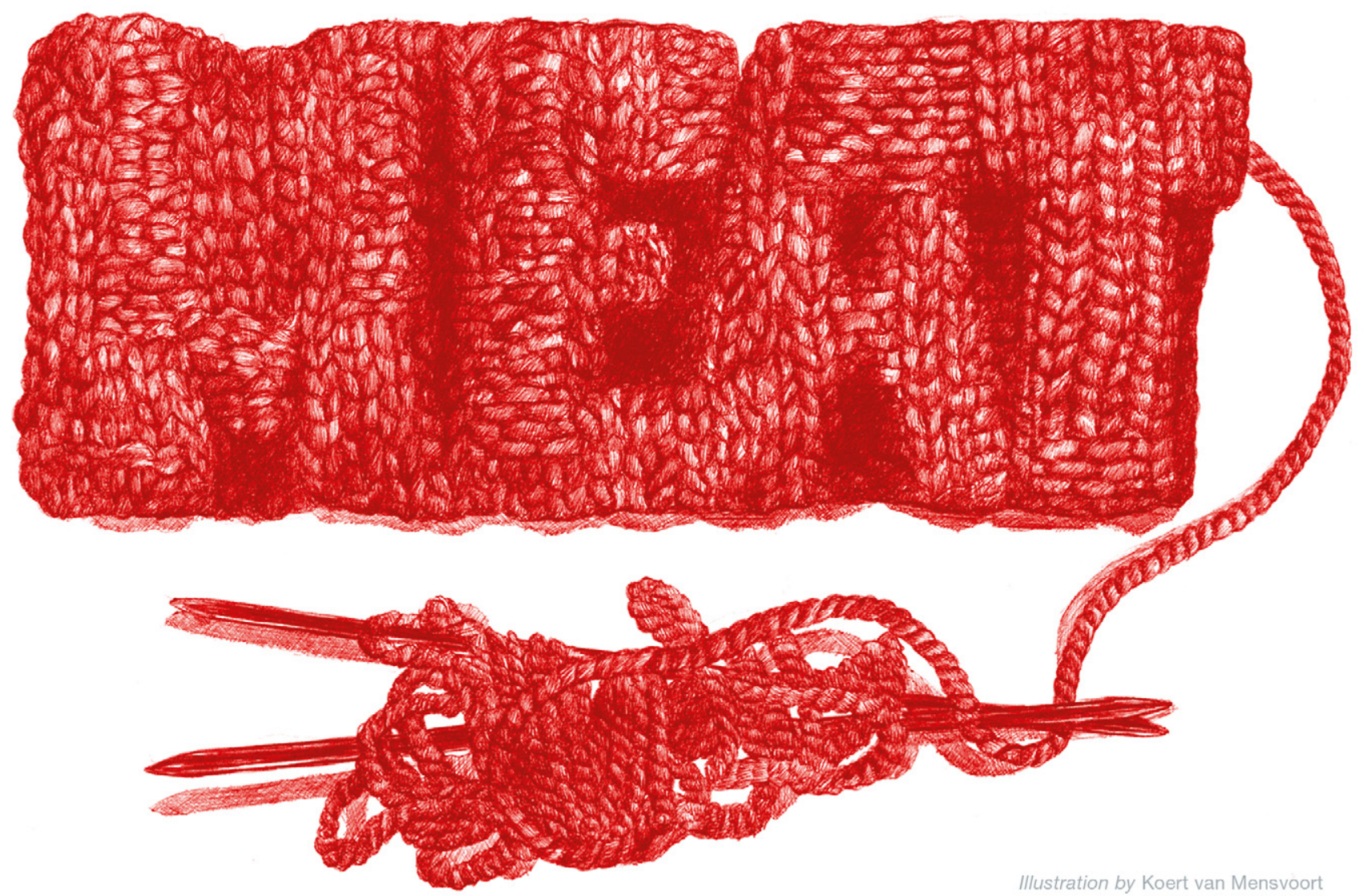

www.mensvoort.com

S uch science-based techniques have been gaining popularity with chefs for years. Switch on a modern cooking show and you will see chefs using molecular techniques such as freezing in liquid nitrogen or compression cookers. Sometimes these tools are used for presentation and sometimes they are employed to save time. Meyers said there are even more tools catching on that bring out bold flavors in meals and provide delicious alternatives for diners with special dietary needs. "A lot of techniques in molecular gastronomy and modern cooking are derived from big companies using these tools to save time and money", he said. "Chefs figured out you can do small batch things with them and have a lot of fun with it".

For example, tapioca maltodextrin is found in a lot of baked goods-from muffins sold at coffee shops to the bargain cookies found at supermarkets. Cooks use it as an "extender" to get more of an ingredient into their mixes, and, in turn, more final product and money, according to Meyers. "I'll use the chemical tapioca maltodextrin which turns any liquid fat into a powder”, he said.
Using the leftover fat from bacon dishes, he drizzles the liquid fat into a food processor with tapioca maltodextrin already in it. "It heats it into powder form. It absorbs the liquid without becoming a paste", Meyers explained. With powdered fat, chefs can add volume to their mixes. Olive oil, truffle oil, and white chocolate are just a few of the fats that can be turned into powders. To diners, the effect looks cool and the taste of the ingredient becomes much stronger and more pronounced, Meyers added.

Sodium citrate added to a warming pot of beer allows any type of cheese to be melted into a rich, creamy concoction. "You can take a nice, aged pecorino that's really hard, shave it down, add it to the sodium citrate and beer, and it will become the texture of Velveeta [soft processed cheese]”, Meyers explained. Using this technique, chefs can create their own cheeses for burgers and sandwiches.

A mong many other food producers, wine makers are having to adapt to the consequences of climate change, including resource depletion, the need for water conservation, reduced soil health, the infestation of invasive species, and an increasing demand for wine. Jure Piskur, professor of molecular and food microbiology at Lund University in Sweden, commented that the quantity of wine produced is not the problem right now, but demand for variety is. Compounding that problem is that the changing climate exposes grapes to higher temperatures. "We have much more sugar in the grape than we did 20 years ago", he said. The result can be excessive levels of alcohol. Piskur said researchers are now visiting vineyards across the world in search of yeasts that could help to mitigate the problem of too much ethanol production, as well as other problems brought on by environmental changes.

Linda Bisson, professor of viticulture and enology at the University of California at Davis, USA, said her research focuses on yeast genetics - $a$ forerunner in improving wine production. The yeast family Saccharomyces is involved in fermentation throughout the 
world in many different environments. The organism is the key to the production of bread, beer, and wine. A bad Saccharomyces strain can lead to problems in Chardonnay or Sauvignon Blanc, including too much residual sugar and extra hydrogen sulfide. "There's no one out there who wants his or her wine to smell like a stinky egg”, Bisson said of the chronic hydrogen sulfide problem that is difficult to predict. "Even a little bit of hydrogen sulfide can suppress our ability to detect a fruit character that's there". Previous solutions included adding copper to the wine, but that has progressively become a less desirable practice.

Early on, researchers looked at genetically tinkering with the yeast's sulfite reduction pathway to prevent it from releasing too much hydrogen sulfide. But often those modifications resulted in bigger problems, such as undesirable aromatic compounds or even unhealthy levels of sulfur dioxide or sulfide. Bisson has taken a different approach: She's screened hundreds of strains of Saccharomyces found in the wild to identify one that does not produce hydrogen sulfide. A vineyard in Italy eventually yielded such a strain, so she sequenced the responsible gene, transferred it into a high hydrogen sulfide-producing yeast, and successfully shut hydrogen sulfide production down.

\section{"... it is the application of science in agriculture that will enable farmers to feed a world population of 9 1/2 billion"}

"We had a GMO solution", Bisson said. "But the problem with that strategy was there was very low acceptance of that in the wine industry because there is low acceptance of that in the high-end restaurant industry". Bisson thus crossbred the strain with others to introduce the desired gene into the background of the modified strain. Now, winemakers who have problems with hydrogen sulfide production can purchase the organic yeast strain commercially and introduce it to the grape must - the freshly pressed grapes. "For me it was important to acknowledge that Mother Nature is a lot smarter than I am and there is something out there that already exists that has the phenotype that I want", Bisson said. Although the hydrogen sulfide problem tends to affect white wines more than reds, the yeast has now found its way into winemakers' concoctions for reds such as Pinot Noir, to bring out more fruity flavors in wines that are typically masked by hydrogen sulfide.

M aking use of yeast genetics does not stop at addressing production problems. Scientists are also searching for different strains that can produce desirable aromas and flavors in beverages. According to Charlie Bamforth, professor of malting and brewing sciences at the University of California at Davis, USA, this is particularly pertinent to controlling compounds and flavor in beer. For example, people with celiac disease or who are gluten intolerant need to avoid beer because wheat and barley contain gluten proteins. "There is an enzyme in the marketplace which will get rid of the last traces of these problematic proteins", Bamforth said. "By adding this enzyme, it is possible to produce beers from barley malt which do not present a risk to people with celiac disease".

Bamforth said that the market for such enzymes is growing, as well as for others that improve the efficiency of beer production. Some enzymes speed up the brewing process or help move it along in high temperatures, while others are responsible for producing low-carbohydrate beer. Many large brewing companies look for enzymes to help them produce beer consistently, efficiently and in large amounts. Smaller companies may be looking at different yeasts or enzymes to produce diverse aromas or flavors. Bamforth said the next step is to figure out how beer deteriorates at the molecular level, especially in a global market where the libation is shipped across the planet through different climates.

n 1931, nine years before becoming prime minister of the United Kingdom, Winston Churchill (1874-1965) wrote an essay about the future of food in Strand magazine: "We shall escape the absurdity of growing a whole chicken in order to eat the breast or wing, by growing these parts separately under a suitable medium. Synthetic food will, of course, also be used in the future. Nor need the pleasures of the table be banished. [...] The new foods will from the outset be practically indistinguishable from the natural products, and any changes will be so gradual as to escape observation".

Science writer Churchill was ahead of his time, and ours. In 2013, a pale burger made international headlines: Gussied up with beetroot juice for coloring, along with breadcrumbs, caramel, and saffron added as taste enhancers, the burger was served up at a press event in London. It was grown in a Dutch laboratory from cattle stem cells and cost US $\$ 330,000$ to culture and produce (Fig 1). Google co-founder Sergey Brin paid the tab.

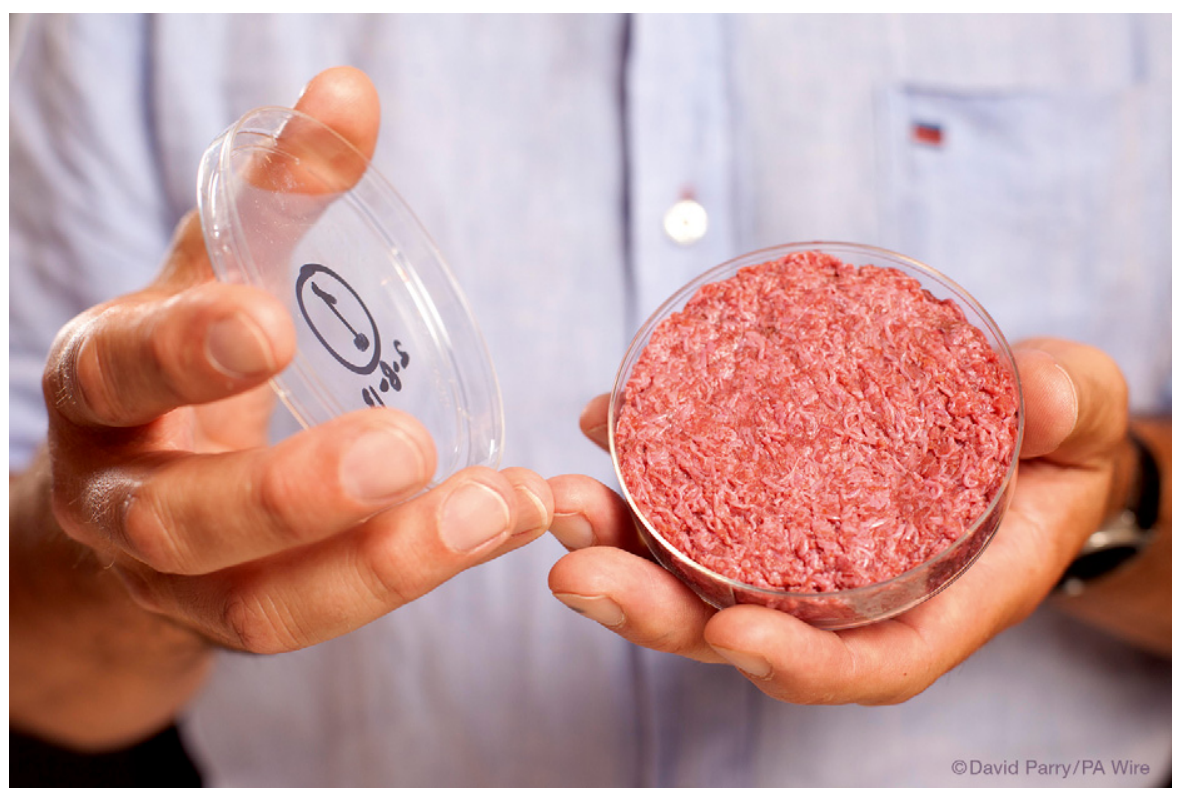

Figure 1. A US\$ $\$ 330,000$ burger made from cultured beef. 
Behind the most expensive burger in the world was researcher Mark Post, Chair of Physiology and Vice Dean of Biomedical Technology at Maastricht University in the Netherlands. "It tasted like meat. It's not perfect, but it's getting there”, Post said about his creation. Originally a medical doctor conducting research into tissue engineering and stem cells, Post said that he started the burger project in light of the growing demand for meat in developing countries. "Meat production is not sufficient to meet the growing demand in the world. It's at its maximum, so it will never be sufficient to meet the growing demand. Also, 20\% of world greenhouse gases come from large stock animals for beef and pork production", Post said. "And, finally, of course, there are animal welfare issues. These are the reasons to start thinking about alternatives for meat production". In a statement, PETA (People for the Ethical Treatment of Animals) welcomed the production of cultured meat, contending that it "will spell the end of lorries full of cows and chickens, abattoirs and factory farming. It will reduce carbon emissions, conserve water, and make the food supply safer" (http://www. dailymail.co.uk/sciencetech/ article-2384715/ At-tastes-meat-Worlds-test-tube-artificial-beefGoogleburger-gets-GOOD-review-eaten-time. html).

cc

... researchers are now visiting vineyards across the world in search of yeasts that could help to mitigate the problem of too much ethanol production...'

To create the burger, the Maastricht laboratory extracted stem cells from cow muscle tissue and cultured them with nutrients and growth-enhancing chemicals for three weeks. The cells were then placed into small petri dishes where they grew to form strips of muscle a centimeter long and a few millimeters thick. From these fibers, pellets and eventually patties could be formed into a pure beef burger.

Post commented that he does not yet have the means to produce adequate amounts of fat to improve the burgers and make them juicier. "It's doable, but it requires a little bit more work to get it into the tissue the way we want it", he said. Likewise, he added, the technology is there, using 3-D printers, to print out steaks. "It's technically more complex to make steaks, but we're definitely going to try that in the coming years. You need to get oxygen and nutrients into the center of the tissue at all times, so it requires a bit more engineering", Post said.

K oert van Mensvoort, a philosopher, performance artist and scientist who runs the Next Nature Lab in the industrial design department at Eindhoven University of Technology in the Netherlands, raised $€ 20,000$ through crowdfunding to develop the In Vitro Meat Cookbook, which contains recipes using laboratory-grown meat and examines the cultural impact of the new food. It promises to examine "labgrown meat not just from a design and engineering perspective, but also from a societal and ethical one. What will holiday dinners look like if in vitro meat replaces turkey? Would you eat meat grown from your own stem cells? Is lab-grown meat kosher? Or vegetarian?" The first print run sold out in just two months last year.

Though Van Mensvoort's ideas can seem fantastical, he is serious in his exploration of how in vitro meat will affect food culture around the world. "Think of meat paint, revived dodo wings, meat ice cream, cannibal snacks, steaks knitted like scarves, and see-through sushi grown under perfectly controlled conditions. Though you can't cook these recipes just yet, they've all been developed with strict culinary rigor to have correct ingredients and cooking techniques", he said about the recipes in his book. "How can we solve the world's protein crisis? While it's possible everyone might switch to insects or tofu, there's a brand-new player on the horizon: lab-grown meat”.

There are regulatory obstacles and public opinion to contend with, however. Post said he fears that cultured beef will be swept into the GMO debate, even though it involves no genetic modification. Regenstein argued that cultured meat is not the solution to the world's growing food problems. "It's a wonderful novelty and I think it's great, but the cells were clearly tasteless because they had to add beet juice and caramel coloring", he said. "This is science doing its thing, and it's wonderful, but is this really going to create a better world with factories with huge amounts of cell culture operating as opposed to having cows eating grass and other byproducts in land that we're going to have to use anyway? [...] And they're making all kinds of claims of reducing energy, but they will still need factories. In terms of a critical analysis of the environmental impact, I'm not sure they will have done something beneficial. I don't see the world being saved".

nstead, Regenstein argues, it is the application of science in agriculture that will enable farmers to feed a world population of $91 / 2$ billion. "We're going to need GMOs so that we can grow in climate change. We're going to need better distribution; we're going to need less food waste; we're going to need a more efficient agriculture, which in my mind is actually factory farming. I think the in vitro meat might even find a niche for itself. But I have a hard time seeing that as really being the way we're going to produce food, and it's still always going to be a hamburger".

\section{"... the technology is there, using 3-D printers, to print out steaks"}

Van Mensvoort acknowledged that cultured meat is a hard sell, noting that many people gag at the thought of laboratory-grown meat. But he pointed out that the same people already purchase completely abstracted meat-sausages, burgers, chicken nuggets - in the supermarket. "People don't recognize the animal in much of the meat that we eat today", he said. He added that cultured meat would likely make an easy entrée as pizza toppings, which people already do not recognize as animal products, while avant-garde chefs and cutting-edge epicures might enjoy experimenting with new food concoctions made from faux meat. "It could provide us with whole new dining experiences with food products that you can hardly envision today. That's more for the connoisseurs; it's not so much for the masses. It's more frivolous, of course, than saving the planet. But it's part of it". And if it helps to ease animal suffering and protect the environment, in vitro meat-as well as other advances in food science-could well become acceptable to the public. 